\title{
Effects of Alternative Ingredients and Processing Conditions on the Quality of Liquid Non-dairy Coffee Creamer: A Review
}

\section{Thithiya Thepkamnoet ${ }^{1}$, Nor Afizah Mustapha ${ }^{1}$, Wan Zunairah Wan Ibadullah $^{2}$ and Roselina Karim ${ }^{1 *}$}

${ }^{1}$ Department of Food Technology, Faculty of Food Science and Technology, Universiti Putra Malaysia, Selangor, Malaysia

${ }^{2}$ Department of Food Science, Faculty of Food Science and Technology, Universiti

Putra Malaysia, Selangor, Malaysia

*Corresponding Author: Roselina Karim, Department of Food Technology, Faculty of Food Science and Technology, Universiti Putra Malaysia, Selangor, Malaysia.
Received: November 29, 2021

Published: December 21, 2021

(C) All rights are reserved by Roselina Karim., et al.

\begin{abstract}
The demand towards coffee and non-dairy products is expected to grow during the next few years due to changing of consumers behavior and perception. This situation provides an opportunity for manufacturers to develop more new variants with improved formulas for health-conscious consumers. However, the usage of traditional ingredients especially in powdered non-dairy coffee creamer has some disadvantages mainly due to the presence of trans-fat and synthetic ingredients. In consideration of these drawbacks, liquid non-dairy coffee creamer either partially or fully substituted with alternative ingredients derived from natural sources are introduced. Nevertheless, incorporation of different types of alternative ingredients and processing conditions used influenced the quality of the final liquid non-dairy coffee creamer. This paper reviewed the effects of alternative ingredients and processing variables on the physicochemical properties, shelf life, sensory attributes, and health aspects of liquid non-dairy coffee creamer. In addition, the application of liquid non-dairy coffee creamer in hot acidic coffee is also described. This review imparts beneficial information on liquid non-dairy coffee creamer's development using potential ingredients and optimal processing conditions in an attempt to improve the quality characteristics of the final products, to satisfy consumers' demand and preferences toward a healthier alternative ingredient.
\end{abstract}

Keywords: Coffee Creamer; Emulsion Stability; Non-dairy Creamer; Non-dairy Liquid Creamer; Physicochemical Properties

\section{Abbreviations}

CLNDC: Coffee Mixed with Liquid Non-dairy Coffee Creamer; DATEM: Diacetyl Tartaric Acid Ester of Mono- and Diglycerides; $\mathrm{d}_{4,3}$ : Volume-weighted Mean Diameter; $\mathrm{d}_{3,2}$ : Surface-weighted Mean Diameters; HACS: Hot Acidic Coffee Solution; HLB: Hydrophiliclipophilic Balance; LNDC: Liquid Non-dairy Coffee Creamer; NDC: Non-dairy Coffee Creamer; O/W: Oil in Water; PNDC: Powder Nondairy Coffee Creamer; QS: Quillaja Saponin; SC: Sodium Caseinate; SL: Soy Lecithin

\section{Introduction}

Coffee is a popular beverage around the world, and it is usually consumed with a coffee creamer [1,2]. Meanwhile, the rising consumer demand for coffee and non-dairy products $[3,4]$ provides manufacturers with an opportunity to develop new variants of non-dairy coffee creamer with improved formulation for healthconscious consumers. Non-dairy coffee creamers (NDC), also known as coffee whiteners are an oil-in-water emulsion product that imitates dairy products [5] and is widely used in the beverages

Citation: Roselina Karim., et al. "Effects of Alternative Ingredients and Processing Conditions on the Quality of Liquid Non-dairy Coffee Creamer: A Review". Acta Scientific Nutritional Health 6.1 (2022): 101-113. 
industry for decades. It is intentionally used to soften the acidic taste and lighten the colour of coffee beverages [2]. Additionally, it has been applied as ingredient in production of several type of food products such as pastry, beverage, ice cream and chocolate [6].

Two forms of non-dairy coffee creamer are available in the market, namely as free-flowing powder and liquid forms. The freeflowing powder non-dairy coffee creamer (PNDC) is commonly made from glucose syrup, hydrogenated vegetable oils, stabilisers, emulsifiers, water, and flavour (optional) as the traditional ingredients [7]. However, of great concern to the consumers is the usage of traditional ingredients such as fully or partially hydrogenated vegetable oil, and emulsifier derived from milk protein i.e. sodium caseinate, which have been related to cardiovascular disease and dairy allergy, respectively $[2,6,8]$. Another drawback of PNDC is the difficulties in dissolution when added to coffee, and also the possibility of forming a non-homogenous appearance in cold beverages [9]. One of the ways to overcome this problem is by introducing alternative ingredients to non-dairy coffee creamer in liquid form (LNDC) to replace the unnecessary use of hydrogenated oil in the product. Improved formula of LNDC with suitable alternative ingredients provides superior benefits than dairy cream and PNDC by reducing unhealthy consequences such as presence of trans-fat and lactose intolerance incidence; improving the product shelf life, and making it more economical $[9,10]$. Moreover, in respond to the current food trends and consumer preferences towards clean label food products [11], the LNDC with improved formulation can be developed by replacing the hydrogenated oil with alternative natural ingredients such as palm olein oil, refined rice bran oil, and rambutan kernel olein $[9,12,13]$. Likewise, alternative emulsifiers such as lecithin, saponins, and carrageenan, can be used to substitute sodium caseinate in LNDC products $[8,9,14,15]$.

However, substituting the traditionally used ingredients with new alternative ingredients consequently affected the quality of LNDC owing to the natural characteristics of the uncommonly used alternative ingredients, which may be ether desirable or undesirable. The quality of non-dairy creamer is affected by the colour and stability of the emulsion [5]. Besides that, processing parameters play an essential role on the quality of LNDC owing to the effect of the fat globule size [9]. Therefore, this review article discusses the effects of alternative ingredients and processing conditions on the quality of liquid non-dairy coffee creamer in terms of the physicochemical properties, sensory attributes, its application in hot acidic coffee, shelf life and health aspects.
Quality characteristics of liquid non-dairy coffee creamer

In an attempt to mimic dairy cream products, producers often imitate the dairy compositions and examine the performance of LNDC by monitoring the quality attributes. Quality attributes of non-dairy creamers are based on the types and concentrations of ingredients, the processing, storage, transport, and application conditions [16]. In addition, producers could also use the physicochemical properties of LNDC and coffee mixed with liquid nondairy coffee creamer (CLNDC), sensory attributes, and health aspects to indicate the quality of LNDC. Table 1 shows the overall quality characteristics of LNDC.

\begin{tabular}{|l|c|}
\hline Condition & \multicolumn{1}{|c|}{ Quality characteristics } \\
\hline During storage & $\begin{array}{c}\text { Retain a uniform emulsion with a constant } \\
\text { viscosity and absence of phase separation, } \\
\text { creaming, sedimentation and gelation }\end{array}$ \\
No color changes \\
\hline With LNDC \\
No feathering or sediment \\
Well-dissolved \\
White colour \\
Delicate taste
\end{tabular}

Table 1: Quality characteristics of liquid non-dairy coffee creamer

(LNDC).

The stability of LNDC could be described by the stability of an emulsion. In other words, it refers to the ability of an emulsion to withstand changes in its properties with time [16] as described by electrostatic and steric stabilisation. Electrostatic repulsion is produced by the adsorption of ionic surfactants on the droplet surface [17]. Oil droplet is coated with the same emulsifier to generate the same electrical charge that will repel each other. However, the sensitivity to $\mathrm{pH}$ and ionic strength of the aqueous phase will result in the emulsifier to lose its charge [16]. In addition, oil droplets can also be stabilised by steric repulsion. A strong repulsion between each droplet is produced from the adsorption of nonionic surfactants or polymers on the droplet surfaces [17]. Shu., et al. reported that the addition decaglycerol monooleate (a non-ionic surfactant) could stabilise the $0 / \mathrm{W}$ nanoemulsion by steric repulsion and this was found to be insensitive to $\mathrm{pH}$ and ionic strength [18].

The LNDC is prone to destabilisation during storage and after addition to hot acidic coffee solution (HACS). Creaming, sedimentation, feathering, oiling-off, flocculation, coalescence and Ostwald 
ripening are terminologies used to describe the quality parameters related to the instability of LNDC. Creaming and sedimentation are due to gravitational separations. A larger droplet size causes creaming and sedimentation in LNDC [19]. The creaming and sedimentation processes could be altered by increasing the continuous phase viscosity, by adding gelling agents or polymer thickeners, decreasing the droplet size by using high-pressure homogenisers or reducing the density difference by adding oil-soluble weighting agents $[17,20]$. Dickinson stated that flocculation might be induced by $\mathrm{pH}$ change or specific ions binding so that the coffee conditions may induce flocculation [21]. In addition, the rate of creaming could be increased by flocculation, owing to its faster movement than single dispersed droplets [22]. Huang., et al. stated that coalescence and Ostwald ripening could form larger droplets size, owing to molecular diffusion of oil molecules through the aqueous phase. The extensive droplet coalescence resulted in oiling-off which could be observed as phases separation [23]. Feathering, is another quality parameter that refers to the white coagulum, flakes, or curds floating on the surface or throughout the beverage [9,21,24]. It could be due to high temperature of coffee which caused the thermal aggregation, high coffee acidity, and electrostatic repulsive interactions in the presence of soluble salts [19].

Ingredients for liquid non-dairy coffee creamer production

The type and concentration of ingredients in the formulation play an essential role on the stability and whitening performance of LNDC. Each ingredient provides a specific function, hence confers the quality characteristics required in LNDC. The main component of LNDC consists of fat or oil, emulsifiers, buffering salt and sugar. Fat or oil and emulsifiers are the most common ingredients that have been substituted with alternative ingredients, and the feasibility of using them in LNDC products has been reported.

Oil

The type of traditional oil commonly used in PNDC formulation is either partially hydrogenated soybean or palm oil. However, the negative aspects of the partial hydrogenation process are related to the issue of trans-fat that is claimed to be unhealthy, followed by the environmental issues on the use of metal catalyst. Conversely, the LNDC is in a liquid state and does not require the use of modified oil, thus preventing the concerns about the trans-fat and ecological impact on consumers [13]. The oil concentration in LNDC could vary from 10 to $15 \%[13,15,25]$. Their primary functions are to provide whitening power and viscosity in LNDC. Many naturally beneficial vegetable oils are commercially available; however, some of these oils are still being studied for future use. Palm kernel oil, soybean oil, rambutan kernel oil, and rice bran oil have been added to LNDC formulations as alternative sources of oil $[9,12,13]$. In addition, Nigella sativa oil and refined kenaf seed oil also have been incorporated in PNDC, hence indicating their potential applications in LNDC [26,27].

\section{Emulsifier}

The main function of emulsifiers is to increase stability against feathering in coffee solution and provide desirable droplet size to achieve a whiter colour in LNDC. Conventional emulsifier for LNDC is $2.00 \% \mathrm{w} / \mathrm{w}$ sodium caseinate which provide a more dairy-like flavour to the product $[9,13,28]$. Moreover, diacetyl tartaric esters of monoglycerides (DATEM) and other low molecular weight emulsifiers such as monoglyceride of fatty acids could also be used as emulsifiers in LNDC $[9,10]$ due to their stronger emulsification properties with high hydrophilic-lipophilic balance (HLB), besides their low price. However, most traditionally used man-made synthetic emulsifiers are of great concern to consumers. Hence, the usage of a combination of protein-polysaccharide, surfactant-protein and surfactant-polysaccharide mixtures with low-medium HLB mainly derived from natural sources, had been claimed to improve the stability of emulsion $[10,29]$ and reduced health concerns.

Saponin has been used as a natural emulsifier in coffee creamers, and it may be derived from various sources. The saponin obtained from the bark of Quillaja saponaria is one of the natural surfactants that is mostly studied in LNDC products. Most quillaja bark has an HLB value of approximately 13.2 [30]. Although the quillaja saponin (QS) is categorised as a non-ionic amphiphilic surfactant, it mainly stabilises $\mathrm{O} / \mathrm{W}$ emulsion by electrostatic repulsion. However, an ionisable carboxyl group on the side chains (glucuronic acid) reduced the electrostatic effect at low $\mathrm{pH}$ and high ionic strength conditions [31,32].

Lecithin, an amphiphilic molecule that is most commonly used in the food industry is extracted from soybeans. Although, soy lecithin is known as one of the common food allergens, Awazuhara., et al. reported that the proteins in soy lecithin and soy oil have little antigenicity related to soybean allergy [33]. In addition, other sources of lecithin may also be used in LNDC, such as sunflower, rice, rapeseed, and canola seed lecithin [34]. However, its interfaces are susceptive to instabilities depending on the variations in $\mathrm{pH}$, ionic strength, and temperature [30]. 
Proteins play a role as emulsifying agents in LNDC owing to their amphiphilic property that can adsorb to the surface of the oil droplet. It could be obtained from high protein foods such as legumes and animal-derived sources such as fish gelatin [5,23,35]. However, protein-based emulsifiers are less stable than other emulsifiers due to their ability to undergo denaturation at high temperature and sensitivity to $\mathrm{pH}[24,36]$.

Polysaccharides derived from natural sources such as seaweed, are known to be stable towards a wide range of temperature and $\mathrm{pH}$. It mainly acts as emulsion stabilisers to prevent coalescence by forming a thick, gel-like steric barrier around the oil droplets [36]. Carrageenan is one of the most widely used polysaccharides in food products, and it is a natural linear sulfated polysaccharide from red edible seaweeds. The $\lambda$-carrageenan has several advantages, including solubility in cold water, no reaction with salt, and non-gelling formation. However, small sizes of oil droplets (less than $200 \mathrm{~nm}$ ) are difficult to form by polysaccharides due to its lower surface-active property [30,37].

\section{Buffering salts}

Buffering salts play an essential role in controlling the $\mathrm{pH}$ and stabilising the protein layer around fat droplets. Buffering salts are added to LNDC at concentrations around $0.10-0.45 \%$. Dipotassium phosphate (E340), sodium citrate (E331), and sodium acetate (E262) are examples of commonly used salts in non-dairy coffee creamer products $[6,9]$. The main characteristics of these salts are white or colourless, water-soluble, crystalline powder or granular crystals, and generally recognised as safe by FDA. Regarding its application in HACS, the overall pH of CLNDC will be minimally changed by the cooperation of buffering salt to prevent the destabilisation of emulsion. In addition, excess amounts of calcium ions from hard water and milk-derived protein could be reduced by the presence of phosphates [24,38].

\section{Sugar}

Sugar provides sweetness to LNDC and is often used in the highest amount compared to other ingredients. The sugar content in LNDC products varies from 2.5 to $65.0 \%$, depending on the type of sugar and formula used $[10,12,13]$. Glucose syrup and corn syrup are commonly used in commercial LNDC products to give the required viscosity and sweetness, and due to its low cost. The addition of corn syrups will increase the viscosity of the continuous phase and slow down the droplet-droplet collisions. On the other hand, adding sucrose to emulsions immediately after homogenization at high concentration (0-40 wt. \%) reduces the rate of particle growth besides providing a better flavour and mouthfeel, and help to prevent browning when used with maltodextrin $[10,24]$.
However, reducing sugar is often avoided because it could lead to Maillard reaction at high temperatures in the presence of protein [10]. High-intensity sweeteners such as Stevia leaf extract (such as Rebaudioside A), erythritol, inulin, acesulfame-k, and sucralose are used in commercial LNDC as alternative sources of sugar. The main advantages of using these alternative sweeteners include fewer amounts are needed, being noncaloric, and do not affect blood sugar or cause tooth decay [39].

\section{Processing of liquid non-dairy coffee creamer}

\section{Basic processing stage}

LNDC is classified as one of the products of an oil-in-water emulsion. It could be formed via main three processes, namely, oil phase preparation, aqueous phase preparation and homogenization as shown in figure $1[8,9,15,19,28,40,23]$. The preparation of the oil phase begun by mixing oil with an emulsifier such as soy lecithin (SL). However, some emulsifiers, like sodium caseinate (SC), quillaja saponin (QS), and carrageenan, performed better if added in the aqueous phase because they are water-soluble and able to hydrate completely for emulsifier efficiency $[13,15]$. The oil should be fully in a liquid state, heated to $60-80^{\circ} \mathrm{C}$, while the emulsifiers should be entirely dissolved or dispersed in oil. Other ingredients, such as sugar and buffering salts, are dissolved in distilled water and homogenised to form the aqueous phase at ambient temperature.

The final stage of LNDC involves homogenisation, and this process is carried out in the presence of emulsifiers to produce a stable emulsion. It can be separated into primary and secondary homogenisation. The oil phase $(10 \%)$ is blended into the aqueous phase (90\%) using a high-speed mixer at 5,000 to $14,000 \mathrm{rpm}$ for 1 - 5 min to form a coarse emulsion known as primary homogenisation. The coarse emulsion has a large droplet size with low kinetic stability separated after storage. Subsequently, the coarse emulsions are passed through equipment that can provide high energy, such as a high-pressure homogeniser, microfluidiser, or ultrasonicator as secondary homogenisation at around 5,000 20,000 psi with 1-2 passes, depending on the equipment used to reduce the droplet size at ambient temperature. The high-pressure homogeniser is commonly used because of its suitability for scaling up in the food industry [32]. It can form a fine emulsion whereby the high pressure forces the coarse emulsion to pass through the narrow valves to break up the droplets. Turbulence, shear stress, and cavitation are phenomena used to describe droplet size reduction [41]. The oil droplet size has become kinetically stable at this step owing to the smaller droplet size. In extending the shelf life of LNDC, a sterilisation process is required. The LNDC is filled into glass bottles or lacquered cans, sterilised at $121^{\circ} \mathrm{C}$ for $15 \mathrm{~min}$, and allowed to cool $[12,13]$. 


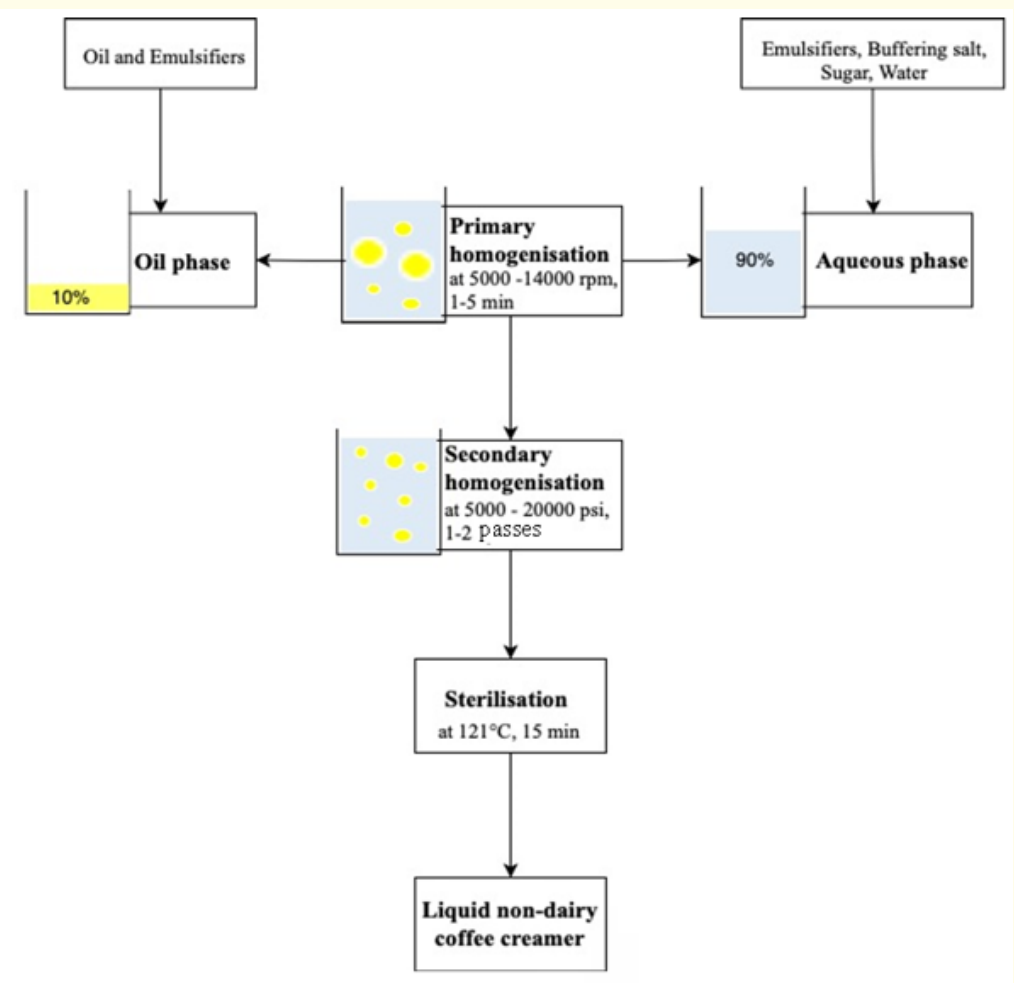

Figure 1: Process flow of liquid non-dairy coffee creamer.

\section{Homogenization and sterilization of LNDC}

The homogenization conditions and sterilization are the main focus of LNDC production due to its effect on the quality of LNDC especially on the sensory attributes and shelf life. Homogenizer type, pressure, and the number of passes affected the particle size and particle size distribution. Even though different oil and emulsifier types are used, a similar trend in droplet size reduction was found when the operating pressure and number of passes were increased $[9,19,42]$. Chung., et al. reported that LNDC produced from high shear mix blender and homogeniser at 1000 psi had particle sizes $\left(d_{4,3}\right)$ of 16 and $1.8 \mu \mathrm{m}$, respectively [19]. Meanwhile, a stable LNDC with the smallest particle size $\left(\mathrm{d}_{4,3}\right)$ around $0.6 \mu \mathrm{m}$ is produced when a high-pressure homogeniser at 5000 psi for one pass is applied. This finding was similar to Soo., et al. who discovered that a homogeniser pressure at 300 bar provided stable LNDC with particle size $\left(\mathrm{d}_{4,3}\right)$ of $0.65 \mu \mathrm{m}$, whereas a 100 bar pressure produced particle size $\left(\mathrm{d}_{4,3}\right)$ of $2.15 \mu \mathrm{m}$ which undergo separation after three days of storage [9]. In relation to the number of passes, the LNDC that is homogenised by microfluidiser at 20,000 psi for four pass- es produced the smallest droplet size of $0.22 \mu \mathrm{m}$ with a uniform creamy appearance [19]. A similar trend was shown for fish oil in water nanoemulsion, but a larger droplet size after three passes in microfluidiser at 206.8 MPa was observed due to over-processing [42]. Besides, emulsions are prone to destabilisation owing to their thermodynamically unstable behaviour. However, Wanthong \& Klinkesorn proved that sterilisation of rambutan kernel oleinbased LNDC had no significant effect on particle size and particle distribution of LNDC, but it affected the colour of LNDC by promoting non-enzymatic browning reactions $[12,13]$.

Physicochemical properties of liquid non-dairy coffee creamer (LNDC) as influenced by alternative ingredients

The types and amounts of alternative ingredients play a vital role in producing a good quality liquid non-dairy coffee creamer (LNDC). Table 2 summarises the effect of alternative ingredients on the quality of LNDC and the stability of coffee mixed with liquid non-dairy coffee creamer (CLNDC). 


\begin{tabular}{|c|c|c|c|c|c|c|c|}
\hline \multirow[b]{2}{*}{ Main ingredient } & \multirow[b]{2}{*}{ Processing variables } & \multicolumn{4}{|c|}{ Physicochemical property of LNDC } & \multirow[b]{2}{*}{$\begin{array}{l}\text { Stability of } \\
\text { CLNDC }\end{array}$} & \multirow[b]{2}{*}{$\begin{array}{l}\text { Refer- } \\
\text { ences }\end{array}$} \\
\hline & & $\begin{array}{c}\text { Particle size } \\
\text { (Fine emulsion) }\end{array}$ & $\begin{array}{l}\text { Zeta- po- } \\
\text { tential } \\
(\mathrm{mV})\end{array}$ & pH & $\begin{array}{l}\text { Colour } \\
\left(L^{*}\right)\end{array}$ & & \\
\hline 1-5\% SL; 10\% MCT & $\begin{array}{l}\text { Coarse emulsion at } 15000 \\
\text { rpm } 1 \text { min; Fine emulsion } \\
\text { at } 20000 \text { psi } 3 \text { passes }\end{array}$ & $\begin{array}{c}\mathrm{d}_{3,2}=0.37-0.11 \\
\mu \mathrm{m}\end{array}$ & - & - & $\begin{array}{l}92.72- \\
88.05\end{array}$ & $\begin{array}{l}\text { Whitish } \\
\text { streaks on the } \\
\text { surface for } 1 \% \\
\text { soy lecithin }\end{array}$ & [8] \\
\hline $\begin{array}{l}0.5 \text { - } 2.0 \% \text { DATEM; } 10 \% \\
\text { palm olein; } 2 \% \mathrm{SC} ; \\
0.1 \% \text { carrageenan }\end{array}$ & $\begin{array}{l}\text { Coarse emulsion at } 5000 \\
\text { rpm } 1 \text { min; Fine emulsion } \\
\text { at } 300 \text { bar } 1 \text { cycle }\end{array}$ & $\begin{array}{c}\mathrm{d}_{4,3}=0.85-0.46 \\
\mu \mathrm{m}\end{array}$ & - & $\begin{array}{l}6.31- \\
4.92\end{array}$ & $\begin{array}{l}93.60 \\
-94.49\end{array}$ & $\begin{array}{l}\text { Small tenden- } \\
\text { cy to feather } \\
\text { at higher \%DA- } \\
\text { TEM }\end{array}$ & [9] \\
\hline $\begin{array}{l}0.5,1,1.5,2.0 \% \text { DATEM; } \\
10 \% \text { soybean oil; } 2 \% \\
\text { SC; } 0.1 \% \text { carrageenan }\end{array}$ & $\begin{array}{l}\text { Coarse emulsion at } 5000 \\
\text { rpm } 1 \text { min; Fine emulsion } \\
\text { at } 300 \text { bar } 1 \text { cycle }\end{array}$ & $\begin{array}{c}\mathrm{d}_{4,3}=0.51-0.61 \\
\mu \mathrm{m}\end{array}$ & - & $\begin{array}{l}5.57- \\
4.91\end{array}$ & $\begin{array}{l}94.25- \\
42.23\end{array}$ & $\begin{array}{l}\text { Great feather- } \\
\text { ing at higher } \\
\text { \%DATEM }\end{array}$ & [9] \\
\hline $\begin{array}{l}35-50 \% \text { water; } 30-40 \% \\
\text { refined rice bran oil; } 10- \\
25 \% \text { glucose syrup }\end{array}$ & $\begin{array}{c}\text { Homogenized using a high } \\
\text { performance commercial } \\
\text { blender at } 13,500 \mathrm{rpm} \text { for } \\
30 \mathrm{~min} \text {; Sterilization at } \\
121^{\circ} \mathrm{C} 15 \mathrm{~min}\end{array}$ & - & - & $\begin{array}{c}5.63- \\
5.88\end{array}$ & $\begin{array}{l}58.43 \\
-68.33\end{array}$ & - & {$[12]$} \\
\hline $\begin{array}{l}0.3 \% \text { DATEM; } 2 \% \text { SC; } \\
10 \% \text { Rambutan kernel } \\
\text { olein }\end{array}$ & $\begin{array}{l}\text { Coarse emulsion at } 9500 \\
\text { rpm } 4 \text { min; Fine emulsion } \\
\text { at } 4351.13 \text { psi (first stage) } \\
\text { and } 435.11 \text { psi (second } \\
\text { stage); Sterilization at } \\
121^{\circ} \mathrm{C} 15 \text { min } 1.1 \text { bar }\end{array}$ & $\begin{array}{l}\text { Z-average = } \\
223.25 \mathrm{~nm}\end{array}$ & -56.51 & - & 89.39 & $\begin{array}{l}\text { No oiling off, } \\
\text { feathering, and } \\
\text { sedimentation }\end{array}$ & {$[13]$} \\
\hline $0.5-2.5 \% \mathrm{QS} ; 10 \% \mathrm{MCT}$ & $\begin{array}{l}\text { Coarse emulsion at } 5000 \\
\text { rpm } 1 \text { min; Fine emulsion } \\
\text { at } 20000 \text { psi } 3 \text { passes }\end{array}$ & $\begin{array}{c}\mathrm{d}_{3,2}=0.36-0.15 \\
\mu \mathrm{m}\end{array}$ & -44 to -53 & 7 & $\begin{array}{l}91.2 \\
-86.0\end{array}$ & $\begin{array}{l}\text { Coalescence } \\
\text { for } 0.5 \% \text { QS }\end{array}$ & {$[14]$} \\
\hline $\begin{array}{l}0 \text { - } 0.175 \% \\
\lambda \text {-carrageenan; } 0.5 \% \text { SC; } \\
0.5 \% \text { SL; } 10 \% \text { MCT }\end{array}$ & $\begin{array}{l}\text { Coarse emulsion at } 12,000 \\
\text { rpm } 1 \text { min; Fine emulsion } \\
\text { at } 5000 \text { psi } 1 \text { pass }\end{array}$ & $\begin{array}{c}\mathrm{d}_{3,2}=0.35-0.38 \\
\mu \mathrm{m}\end{array}$ & -35 to -33 & 7 & - & $\begin{array}{c}\text { Extensive } \\
\text { droplet coales- } \\
\text { cence at low } \\
\lambda \text {-carrageenan } \\
\text { concentration } \\
\text { at pH5 }\end{array}$ & {$[15]$} \\
\hline $\begin{array}{l}1 \%, \mathrm{w} / \mathrm{v} \text { FG or GFOA; } \\
10 \% \text { w/w canola oil }\end{array}$ & $\begin{array}{l}\text { Coarse emulsion at } 13,000 \\
\text { rpm for } 3 \text { min; Fine emul- } \\
\text { sion at } 1400 \text { bar } 2 \text { passes }\end{array}$ & $\begin{array}{c}\mathrm{d}_{3,2}=695 \\
\mathrm{~nm}(\mathrm{FG}) \text {, and } 631 \\
\mathrm{~nm}(\mathrm{GFOA})\end{array}$ & $\begin{array}{c}24.03 \\
(\mathrm{FG}) \text {, and } \\
24.87 \\
\text { GFOA) }\end{array}$ & - & - & $\begin{array}{l}\text { Fish gelatin } \\
\text { alone provide } \\
\text { flocculation } \\
\text { and coales- } \\
\text { cence highly } \\
\text { during storage }\end{array}$ & {$[23]$} \\
\hline $0.5-1.5 \%$ SL; $10 \%$ MCT & $\begin{array}{l}\text { Coarse emulsion at } 15000 \\
\text { rpm } 1 \text { min; Fine emul- } \\
\text { sion at } 5000 \text { psi } 1 \text { pass by } \\
\text { microfluidizer }\end{array}$ & $\mathrm{d}_{3,2}=2-0.56 \mu \mathrm{m}$ & $\begin{array}{c}-38.49 \text { to } \\
-34.80\end{array}$ & 7 & $\begin{array}{c}81.57- \\
87.55\end{array}$ & $\begin{array}{l}\text { Feathering } \\
\text { for } 0.5 \% \text { soy } \\
\text { lecithin but } \\
\text { no extensive } \\
\text { flocculation or } \\
\text { coalescence }\end{array}$ & {$[40]$} \\
\hline
\end{tabular}

Table 2: Effects of alternative ingredients on the physicochemical properties of LNDC and stability of coffee mixed with liquid non-dairy coffee creamer.

LNDC: Liquid non-dairy coffee creamer, CLNDC: Coffee mixed with LNDC, FG: Fish gelatin, GFOA: Fish gelatin glycosylated by octenyl succinate anhydride - gum Arabic, MCT: Medium chain triglyceride, QS: Quillaja saponin, $\mathrm{d}_{4,3}$ : Volume-weighted mean diameter, $\mathrm{d}_{3,2}$ : Surface-weighted mean diameters, Z-average: The volume intensity mean diameter, DATEM: Diacetyl Tartaric Acid Ester of Mono- and Diglycerides, SC: Sodium caseinate, SL: Soy lecithn 


\section{Particle size and particle size distribution}

The particle size and particle size distribution are parameters that described the properties of emulsion in food products and influence the shelf life, appearance, texture, and flavour of LNDC $[15,42]$. An acceptable and desirable LNDC should has small particle size and be monodisperse with a narrow size distribution. Commercial LNDC has particle size and particle size distribution of $_{\mathrm{d} 4,3} \approx 0.30 \mu \mathrm{m}$ and 2.73 (span), respectively, at a limited $\mathrm{pH}$ range of 7 to $5.5[9,25]$.

Oil content did not affect the particle size and particle size distribution of LNDC. Chung., et al. observed a particle size $\left(\mathrm{d}_{4,3}\right)$ of around $0.6 \mu \mathrm{m}$ for 1.0 to $15.0 \%$ oil content when the ratio of emulsifier and oil was at a constant ratio of 1:15 and this is described by sufficient emulsifier covering all the oil droplets [25]. Conversely, Zheng., et al. found that the particle size increased as the oil content was increased from 5 to $20 \mathrm{~g}$ at a constant amount of $1 \mathrm{~g}$ of sodium caseinate or soy protein isolate or sugar ester for Sea Buckthorn $\mathrm{O} / \mathrm{W}$ emulsions due to insufficient emulsifier and higher viscosity leading to a reduction in homogenisation efficacy [43]. In terms of oil type, polar flavour oil could induce Ostwald ripening. Dahlawi., et al. reported that orange oil-based oil in water nanoemulsions exhibited a large mean droplet size of approximately $800 \mathrm{~nm}$ due to the high-water solubility characteristics [44].

Based on table 2, increasing DATEM, quillaja saponin (QS), and soy lecithin (SL) concentrations reduced the particle size in the LNDC model. The higher emulsifier concentration without destabilization mechanism showed that particle size diameter ranged from 0.1 to $0.6 \mu \mathrm{m}$ with narrow size distribution when compared to a lower concentration of emulsifier with $0.3-2.0 \mu \mathrm{m}$. However, excess emulsifiers could not break up the oil droplet, causing a larger droplet size and a widening particle size distribution [9]. Chung., et al. and Dahlawi., et al. stated that the more emulsifiers are available, the more rapid and complete the coating of oil droplets surface will be, resulted in a decrease in interfacial tension and resistance to coalescence during homogenization $[8,44]$.

QS has an excellent ability of promoting particle size reduction compared with lecithin (soy, egg, and rapeseed), sodium caseinate, and pea protein $[14,40,45]$, owing to its higher surface-active property, faster rate of adsorption to the droplet surfaces, lower surface load, and more effective to decrease the Laplace pressure (the difference in the pressure between inside and outside) of the oil droplets. However, combination of QS with SL or SC could be added to LNDC to provide a smaller oil particle size [46]. In contrast, polysaccharide such as gum Arabic, may not reduce the droplet size when it is used alone [36] or in combination with high surface-active activity at neutral $\mathrm{pH}$ of $\mathrm{O} / \mathrm{W}$ emulsion [15], owing to its slower ability to adsorb to the oil surface, and insufficient or excess amount led to larger droplet and depletion of flocculation.

The stability of CLNDC was studied in HACS at pH around 4.44.9 and $80-85^{\circ} \mathrm{C}[9,14]$. Chung., et al. and Wanthong and Klinkesorn found that the LNDC level did not affect the particle size and particle size distribution of CLNDC $[13,25]$. The benefit of using an increased concentration of alternative emulsifiers is to overcome the acidic condition, which helps to prevent phase separation, feathering or coagulation. A minimal change of particle size with narrow size distribution at the highest emulsifier concentration was observed when compared to a lower concentration of emulsifiers $[8,9,13-15]$. It was noted that $5.0 \%$ soy lecithin and $2.5 \%$ QS are considered the most efficient emulsifiers to resist HACS conditions as it provides minimal changes in droplet size [8]. Besides, researchers may simulate HACS conditions by adjusting the temperature and $\mathrm{pH}$ of the $\mathrm{O} / \mathrm{W}$ emulsion model. Salminen., et al. and Zhu., et al. stated that a minimal change in droplet size of $0 / \mathrm{W}$ emulsion stabilised solely by tea saponin, QS, and lecithin at 30-90 ${ }^{\circ} \mathrm{C}$ for 30 min prevent destabilization $[30,47]$. However, globular protein such as pea protein and low molecular emulsifiers such as TWEEN are susceptible to high temperature and formed aggregation at $75-85^{\circ} \mathrm{C}$ and larger droplet size at $90^{\circ} \mathrm{C}$, respectively $[44,48]$. In terms of $\mathrm{pH}$ adjustment, $\mathrm{QS}$ alone stabilised $0 / \mathrm{W}$ emulsion and showed stability at $\mathrm{pH} 3$ with a particle size $\left(\mathrm{d}_{4,3}\right)$ around $0.28 \mu \mathrm{m}$. In contrast, Koo., et al. found that bridging flocculation was shown in $0 / \mathrm{W}$ emulsion produced by a combination of $0.5 \%$ SL and $0.5 \%$ SC at pH 5. However, adding $0.175 \%$ lambda carrageenan could improve stability [15].

\section{Zeta potential}

Zeta potential determination is particularly important for characterising LNDC as it indicates the stability of the emulsion over time. The bulk physicochemical and sensory properties of food emulsions are governed by the magnitude and signs of the electrical charge on the droplets caused by adsorption of ionic compounds [16]. Typically, good physical stability emulsions are presented at equal or more than $\pm 30 \mathrm{mV}$ [6]. The black coffee solution showed a zeta-potential of around $-7.5 \mathrm{mV}$ at $\mathrm{pH} 4.9$, while the zeta-potential of the droplets of commercial LNDC is around $-44 \mathrm{mV}$ at pH 7 and this is further reduced to $+13 \mathrm{mV}$ at $\mathrm{pH} 3.5$ [14]. The 
LNDC formulated with sodium caseinate is prone to be unstable at lower $\mathrm{pH}$ owing to the near isoelectric point, hence alternative emulsifiers are added to improve the stability of LNDC. Addition of alternative emulsifier in LNDC formulation produced zeta-potential between -30 to $-72 \mathrm{mV}$ with a good stability, comparable to commercial LNDC (Table 2). The zeta-potential of the LNDC was significantly influenced by $\mathrm{pH}$ and emulsifier type. At neutral $\mathrm{pH}$, most of the LNDC was stabilised by electrostatic repulsion from emulsifiers. This could be explained by the natural anionic of DATEM, the negative charge at $\mathrm{pH}$ over isoelectric point for SC, the ionisation of carboxylic acid groups on the surfactant at higher $\mathrm{pH}$ values for $\mathrm{QS}$, and the presence of phosphate and carboxyl groups associated with their polar head groups for SL $[8,9,13,14]$.

When LNDC was added to HACS, the reduction of zeta-potential value was observed in CLNDC for all formulations studied when compared to the initial LNDC [13-15,40] probably because most of them are ionic emulsifiers that are susceptible to $\mathrm{pH}$ changes especially at lower $\mathrm{pH}$ and are referred as marginally stable. In addition, Chung., et al. stated that the adsorption of cationic calcium ions from hard water to oil droplets and charged components in a coffee solution contributed to the changes of electrical signals [14]. It was noted that a combination of $0.50 \%$ soy lecithin, $0.50 \%$ sodium caseinate, and $0.175 \%$ lambda carrageenan in $0 / \mathrm{W}$ emulsion produced a large particle size $\left(\mathrm{d}_{3,2}\right)$ of around $0.8 \mu \mathrm{m}$ indicating destabilisation. However, at the highest zeta-potential $(-27 \mathrm{mV})$ a stable emulsion was formed due to the increase in the electrostatic repulsion between the droplets from lambda carrageenan and the higher viscosity of the aqueous phase.

pH

LNDC is added to coffee to soften the acidic taste, as shown by the increased $\mathrm{pH}$ of hot coffee solutions. The initial pH of LNDC is dominated by the initial $\mathrm{pH}$ of an ingredient, i.e. oil and emulsifier. Soo., et al. discovered that the initial $\mathrm{pH}$ of palm olein is higher than soybean and DATEM that served as acidic emulsifiers. The commercial LNDC had the highest $\mathrm{pH}$ value of 7.22 [9] and produced a $\mathrm{pH}$ of 6.3 in CLNDC (14) by cooperation with buffering salt to maintain $\mathrm{pH}$, while the alternative ingredient-based LNDC provides $\mathrm{pH}$ around 5.22 to $5.57[13,25,40]$. All models of LNDC produced from various alternative ingredients increased the $\mathrm{pH}$ of HACS lower than commercial LNDC, owing to the differences in ingredients used, i.e. using phosphate buffer ( $\mathrm{pH} 7$ ). Chung., et al. analysed the $\mathrm{pH}$ change of CLNDC produced from SL or QS and found that the
pH of HACS had increased from pH 4.9 to around pH 6.0 in coffee containing $30 \mathrm{~mL}$ LNDC [14].

\section{Color}

Whitening is an essential ability of LNDC that contributes to the overall sensory attributes and consumer appeal [14]. Based on Table 2, the types and concentrations of emulsifiers and particle size affected the lightness of LNDC. The LNDC produced by combining $2.00 \% \mathrm{w} / \mathrm{w}$ DATEM and $2.00 \% \mathrm{SC}$ had the highest lightness compared to commercial LNDC, owing to the cooperation of SC. On the other hand, the LNDC formulated solely from naturally derived emulsifiers had the highest lightness, with values around 91.20 for $5.00 \%$ SL and 92.72 for $0.50 \%$ QS. In addition, the reduced-fat LNDC formula could be using at least $7.5 \%$ medium-chain triglyceride oil that provides lightness similar to commercial LNDC [25]. Chung., et al. Huang., et al. and Soo., et al. discovered that increasing SC, fish gelatin, and DATEM concentration as emulsifiers produced higher lightness in LNDC due to the smaller droplet when the emulsifier concentration was increased $[9,23,40]$. Droplet size should be in the range of 100 to $200 \mathrm{~nm}$ to provide the most efficient scatter of light waves $[8,40,49]$. Conversely, Chung., et al. found that increasing QS and SL concentration decreased the lightness of LNCD, owing to its natural colour $[8,14]$. However, sole soy lecithin provided yellowness to LNDC that could be improved by adding a low sodium caseinate concentration $(\sim 0.50 \%)$ [40]. Different emulsifying properties, light reflection from surfactant surfaces, differences in particle size distribution, and droplet size that could alter the degree of light scattering are explanations used to describe the different results of studies $[8,9,14]$. In terms of whiter coffee, the lightness of HACS was increased after adding LNDC. The HACS was indicated as whiter coffee by the instrumental lightness values when increasing LNDC level from 5 to $30 \mathrm{~mL}$. Higher droplet concentrations could describe this scenario due to the increase in the fraction of light back-scattered [14].

\section{Viscosity}

Viscosity may be defined as the internal friction of a liquid, the resistance to shear or flow. Shear viscosity is used to describe the creaminess of emulsion-based food products that is essential in sensory evaluation. A moderate increase in viscosity could improve the body and mouthfeel of LNDC. The viscosity of commercial LNDC is around $2 \mathrm{mPa} \cdot \mathrm{s}$ [25], however if the LNDC is too viscous, it will result in the feathering of CLNDC [28]. High viscosity will not provide emulsion stability [23], but could be a sign of 
droplet aggregation [24]. Increasing oil contents provide higher viscosity of LNDC [12]. Chung., et al. observed that increasing oil content from 1.0 to $15.0 \%$ showed an increase in viscosity of LNDC from 0.9 to $1.5 \mathrm{mPa} \cdot \mathrm{s}$ [25]. Soo., et al. revealed that soybean oil-based LNDC showed lower viscosity (3.32 - $4.97 \mathrm{mPa} \cdot \mathrm{s}$ ) when compared to palm oil-based LNDC (3.62- $6.10 \mathrm{mPa} \cdot \mathrm{s})$, owing to soybean oil having a lower viscosity than palm olein, a less rigid molecular structure and a higher degree of unsaturation [9]. Koo., et al. discovered that LNDC containing $\kappa$-carrageenan had a higher apparent shear viscosity than those containing $\lambda$-carrageenan at pH 5 and 7 in LNDC, owing to their tendency to form stiff helices [15]. Furthermore, according to Consoli., et al. the droplet size affected the rheological properties of the emulsion [50]. Huang., et al. found that smaller droplet sizes of LNDC stabilised by fish gelatin glycosylated by octenyl succinate anhydride-gum Arabic (OSA-GA) provided lower viscosity when compared with LNDC- stabilised by fish gelatin alone (larger droplet size). This could be due to the adsorption of OSA-GA particles to the oil droplet surface, resulting in unavailability of emulsifier in the aqueous phase [23].

\section{Shelf life of liquid non-dairy coffee creamer}

The shelf life of commercial LNDC products is around 45-90 days at refrigerated conditions [2]. Sodium azide at a concentration of $0.02 \%$ could be added as a preservative to inhibit microbial growth $[13,23]$. However, the shelf life of LNDC can be extended by sterilisation process. Although the emulsion is known to be thermodynamically unstable, Wanthong \& Klinkesorn found that the sterilisation process did not affect the stability of LNDC produced from rambutan kernel olein [13]. The absence of creaming, coalescence, and flocculated particles and colour change when stored at $25^{\circ} \mathrm{C}$ for 150 days may be due to the anionic nature and higher hydrophilic part of DATEM. Emulsifiers, thickening agents, and weighting agents (density-adjusting agents) are used to provide long-term stability of beverage emulsions [51]. Salminen., et al. observed that $0.5-1.0 \%$ Quillaja saponin (QS) stabilised 0/W emulsions and remained physically stable throughout the 21-days of storage time explained by a strong electrostatic repulsion and a thick layer on the oil droplet interface [30]. Soo., et al. reported that $0.02 \mathrm{~g} / \mathrm{kg}$ carrageenan was added to palm olein-based to inhibit upward movement of oil droplets (creaming) [9]. They found that the $\mathrm{pH},{ }^{\circ} \mathrm{Brix}$, viscosity, and colour of LNDC were not affected during 15 days of storage; however, the droplet size increased owing to a less efficient emulsification process. Furthermore, when 0/W emulsion was stored at chilled conditions, the oil droplets were partially crystallised and susceptible to partial coalescence, leading to droplet aggregation and emulsion instability. However, when the aqueous phase became crystallised at frozen conditions, the oil droplets were forced to become closer, causing interfacial emulsifier layers of droplet disruption as a result of ice crystals penetration [24]. Salminen., et al. discovered that $0 / \mathrm{W}$ emulsion stabilised with egg lecithin or QS was unstable at $-28^{\circ} \mathrm{C}$, and indicated creaming, oiling-off, and phase separation after thawing [30]. In term of lipid oxidation, inclusion of QS in oil in water emulsion prevent lipid oxidation [52,53] due to its free radical scavenging activity which is about 10 -fold greater than lecithin and 55 -fold greater than Tween 80 [53].

Sensory properties of coffee mixed with liquid non-dairy coffee creamer

The sensory attribute of a food product is of outmost importance as it affects consumers' acceptance and purchasing decision. As discussed earlier, substitution of LNDC with alternative ingredients clearly affected the physicochemical properties of the final product, hence it will also influence the odour, appearance, taste, flavour and overall acceptability of CLNDC from consumer's point of view. Precipitation, feathering, and poor solubility are among the unacceptable appearance of CLNDC found to be significantly affected by increasing amounts of peanut milk [35] and the presence of high insoluble particles in the milk. In addition, a more significant feathering effect was observed in soybean oil-based LNDC compared to palm oil-based LNDC substituted by sodium of caseinate and DATEM at the same concentrations [9] as explained by the higher initial $\mathrm{pH}$ of palm oil than soybean oil. In term of colour, Thuy., et al. and Soo., et al. reported that the preference for colour of soybean oil-based LNDC before and after adding to coffee solution was not significantly difference compared with the commercial LNDC $[9,12]$. Furthermore, Malundo., et al. discovered that LNDC substituted by at least $50.0 \%$ of peanut milk resulted in a bitter taste [35] due to saponins presence in the peanut skin. In another study, panellists were able to detect bitter taste in Nigella sativa oil based-PNDC due to the high phenolic content [27]. Nevertheless, increasing the sweetness concentration may help to improve the overall liking of LNDC. LNDC formulated using a higher concentration of glucose syrup (25\%) was found to obtain the highest overall average liking scores [12]. With regards to odour issue, majority of the panellists could not accept the beany soybean aroma caused by the 2-pentylfuran compound in soybean oil-based LNDC [9]. Con- 
versely, Thuy., et al. in their study on the quality of sterilised liquid non-dairy creamer, reported that substituting palm oil with refined rice bran oil did not significantly affect the aroma after addition to hot coffee solution [12] probably due to the neutral taste and delicate flavor of the rice bran oils.

Health aspects of liquid non-dairy coffee creamers

Partially hydrogenated vegetable oil is the source of trans fatty acids that are related to health disorders when consumed for a long time [54,55]. In addition, even though a coffee creamer is labelled as non-dairy, it may still contain milk-derived proteins such as casein and sodium-caseinate as stated on the label of a commercial non-dairy creamer. This could be misleading to dairy intolerance consumers, leading to health problems. However, many researchers have produced LNDC from various beneficial alternative ingredients to improve the quality of LNDC. The presence of functional components such as bioactive compounds, omega-3, dietary fibre in LNDC is important to be considered. The natural health benefits of these functional ingredients also contribute to the health benefits of LNDC products. Quillaja saponins as alternative emulsifiers contain biological activities such as antibacterial, antiviral and antifungal [56]. In addition, the arachidic acid (C20:0) is the main fraction of rambutan seed fats that could provide necessary functions to the nervous system, skeletal muscle, and immune system of humans $[13,57,58]$. Moreover, polysaccharides as natural emulsifiers such as gum Arabic cannot be digested in the intestine and used as a prebiotic in healthy food such as yoghurt [59]. It is fermented in the colon and releases short fatty acid chains, e.g. acetate, propionate that provide energy on eukaryotic cells $[26,60]$. Nevertheless, the processing of LNDC could degrade the beneficial substances. Rice bran oil contains approximately $40 \%$ of oleic acid and is rich in antioxidants, e.g. tocopherols, tocotrienols, $\gamma$-oryzanol was substituted for palm oil [12]. Nevertheless, the sterilisation process of LNDC could reduce the tocopherols at higher temperatures and more extended time. High temperature also affected thymoquinone content in PNDC. Thymoquinone is the bioactive component of Nigella sativa that lowers the blood cholesterol and prevent cardiovascular diseases, owing to the significant level of sterols, i.e. $\beta$-sitosterol (44-54\%) [61,62]. It has been found that spray-dried and agglomerated powders of PNDC contained lower thymoquinone content [27].

\section{Conclusion}

The usage of new alternative ingredients especially from natural sources for the production of healthy LNDC are reviewed. Alter- native oils such as palm olein oil, refined rice bran oil, rambutan kernel olein, and alternative emulsifiers such as soy lecithin, QS, and carrageenan, are potential ingredients for producing a good quality LNDC that performs well in CLNDC. However, the influences of these alternative ingredients on the final product quality, stability and health benefits need to be considered to meet consumers expectation and satisfaction. Type and concentration of ingredients in the formulation and application of specific processes such as homogenization and sterilization affected the physicochemical property, sensory acceptability and shelf life of LNDC. This review highlights the importance of choosing the suitable type and concentration of alternative ingredients for the formulation of a healthy LNDC and the role of using the correct processing technique for production of LNDC with acceptable physicochemical and sensory properties. Further work on optimizing the content of alternative ingredients and processing variables is deemed necessary in an attempt to improve the overall quality of LNDC in terms of emulsion stability, increase stability against feathering in coffee solution, creating the proper amount of fat agglomeration to achieve the desirable whitening effect and provide acceptable creaminess and product mouthfeel with extended shelf life. In addition, innovation of LNDC using beneficial local ingredients containing bioactive compounds with functional properties is recommended to valueadd LNDC products.

\section{Bibliography}

1. Lim L T., et al. "Coffee: One of the Most Consumed Beverages in the World". In Comprehensive Biotechnology. $3^{\text {rd }} \mathrm{Ed}, 4.22$ ( 2019): 275-285.

2. Pordy W T. "Low fat, low cholesterol, and low calorie dairy creamer". Google Patents (1994).

3. Markets and Markets. "Dairy Alternatives Market by Source (Soy, Almond, Coconut, Oats, Rice, Hemp), Application (Milk, Yogurt, Ice creams, Cheese, Creamers), Distribution Channel (Supermarkets, Health Food Stores, Pharmacies), Formulation, and Region - Global Forecast to 2026". (2021).

4. Mordor Intelligence. "Coffee market- growth, trends, COVID-19 impact, and forecasts (2021-2026)" (2021).

5. Rosida D F., et al. "A comparative study of non-dairy cream based on the type of leguminosae protein source in terms of physicochemical properties and organoleptic". Agriculture and Agricultural Science Procedia 9 (2016): 431-439.

6. Biao Wang and Jie Liu. "Trans-free non-dairy creamer prepared from enzymatic interesterification of soybean oil and 
fully hydrogenated soybean oil". Journal of Food Process Engineering 37.4 (2014): 339-348.

7. Yusoff M S A., et al. "Palm-based non-hydrogenated creamer". MPOB Information Series 196 (2003).

8. Chung C., et al. "Impact of electrostatic interactions on lecithin-stabilized model o/w emulsions". Food Biophysics 13.3 (2018a): 292-303.

9. Soo Y N., et al. "Fabrication of oil-in-water emulsions as shelfstable liquid non-dairy creamers: Effects of homogenization pressure, oil type, and emulsifier concentration". Journal of the Science of Food and Agriculture 101.6 (2021): 2455-2462.

10. Sher AA., et al. "Liquid creamer composition and process". United States Patent, US 2013/0122178 A1 (2013).

11. Allied Market Research. Non-Dairy Creamer Market by Origin (Almond, Coconut, Soy and Others), Form (Powdered and Liquid), Nature (Organic and Conventional), and Sales Channel (Supermarkets/Hypermarkets, Online Stores, Departmental Stores, Online Stores, and Others): Global Opportunity Analysis and Industry Forecast, 2021-2027. 25 July 25. (2021).

12. Thuy T., et al. "Production and Quality of Sterilized Liquid Nondairy Creamer from Refined Rice Bran Oil". The $18^{\text {th }}$ Food Innovation Asia Conference 2016 (FIAC 2016) Food Research and Innovation for Sustainable Global Prosperity (2016).

13. Wanthong, T., et al. "Rambutan (Nephelium lappaceum) kernel olein as a non-hydrogenated fat component for developing model non-dairy liquid creamer: effect of emulsifier concentration, sterilization, and pH". Journal of Food Science and Technology 57.12 (2020): 4404-4413.

14. Chung C., et al. "Formulation of food emulsions using natural emulsifiers: Utilization of Quillaja saponin and soy lecithin to fabricate liquid coffee whiteners". Journal of Food Engineering 209 (2017a): 1-11.

15. Koo C K W., et al. "Impact of sodium caseinate, soy lecithin and carrageenan on functionality of oil-in-water emulsions". Food Research International 123 (2019): 779-789.

16. McClements DJ. "Food Emulsions: Principles, Practice, and Techniques". $2^{\text {nd }}$ ed, CRC Press (2015).

17. Tadros TF. "Emulsion Formation, Stability, and Rheology". In Emulsion Formation and Stability. Wiley-VCH (2013).

18. Shu G., et al. "Formulation and stability assessment of ergocalciferol loaded oil-in-water nanoemulsions: Insights of emulsi- fiers effect on stabilization mechanism". Food Research International 90 (2016): 320-327.

19. Chung C., et al. "Influence of homogenization on physical properties of model coffee creamers stabilized by quillaja saponin". Food Research International 99 (2017c): 770-777.

20. Williams P A., et al. "Chapter 1 - Introduction to food hydrocolloids". In G. O. Phillips and P. A. Williams (Eds.), Handbook of Hydrocolloids. $3^{\text {rd }}$ ed, Woodhead Publishing (2021).

21. Dickinson E. "Hydrocolloids and Emulsion Stability". In Handbook of Hydrocolloids. $2^{\text {nd }}$ ed, Woodhead Publishing Limited (2009).

22. Dickinson E., et al. "Creaming and flocculation of oil-in-water emulsions containing sodium caseinate". Journal of Colloid and Interface Science 185.2 (1997): 515-529.

23. Huang T., et al. "Glycosylated fish gelatin emulsion: Rheological, tribological properties and its application as model coffee creamers". Food Hydrocolloids 102 (2020): 105552.

24. McClements DJ. "Whey Protein-Stabilized Emulsions". In Whey Processing, Functionality and Health Benefits (eds C.I. Onwulata and P.J. Huth). Wiley-Blackwell (2008).

25. Chung, C., et al. "Impact of oil droplet concentration on the optical, rheological, and stability characteristics of $\mathrm{O} / \mathrm{W}$ emulsions stabilized with plant-based surfactant: Potential application as non-dairy creamers". Food Research International 105 (2018b): 913-919.

26. Chew S C., et al. "In-vitro bioaccessibility of spray dried refined kenaf (Hibiscus cannabinus) seed oil applied in coffee drink". Journal of Food Science and Technology 57.7 (2020): 25072515.

27. Mohammed N K., et al. "Production of functional non-dairy creamer using Nigella sativa oil via fluidized bed coating technology". Food and Bioprocess Technology 12.8 (2019): 13521365.

28. Golde AE and Schmidt KA. "Quality of coffee creamers as a function of protein source". Journal of Food Quality 28.1 (2005): 46-61.

29. Costa C., et al. "Emulsion formation and stabilization by biomolecules: The leading role of cellulose". Polymers 11.10 (2019): 1-18.

30. Salminen H., et al. "Formation and stability of emulsions stabilized by Quillaja saponin-egg lecithin mixtures". Journal of Food Science 85.4 (2020): 1213-1222. 
31. Schmitt C., et al. "Saponins: A renewable and biodegradable surfactant from its microwave-assisted extraction to the synthesis of monodisperse lattices". Biomacromolecules 15. 3 (2014): 856-862.

32. Schreiner T B., et al. "Formulation and optimization of nanoemulsions using the natural surfactant saponin from Quillaja bark". Molecules 25.7 (2020): 1538.

33. Awazuhara H., et al. "Antigenicity of the proteins in soy lecithin and soy oil in soybean allergy". Clinical and Experimental Allergy 28. 12 (1998): 1559-1564.

34. Kinyanjui, T., et al. "Organic Emulsifiers". Encyclopedia of Food Sciences and Nutrition (2003): 2070-2077.

35. Malundo T M M., et al. "Sensory quality and performance of spray-dried coffee whitener from peanuts". Journal of Food Science 57.1 (1992): 222-226.

36. Tan T B., et al. "Effect of polysaccharide emulsifiers on the fabrication of monodisperse oil-in-water emulsions using the microchannel emulsification method". Journal of Food Engineering 238 (2018): 188-194.

37. Yang Y., et al. "Formation and stability of emulsions using a natural small molecule surfactant: Quillaja saponin (Q-Natura$\mathrm{le}^{\circledR}$ ). Food Hydrocolloids 30.2 (2013): 589-596.

38. Campbell L J. “Dairy Substitutes”. In Kirk-Othmer Encyclopedia of Chemical Technology. Wiley (2020).

39. Tandel KR. "Sugar substitutes: Health controversy over perceived benefits". Journal of Pharmacology and Pharmacotherapeutics 2.4 (2011): 236-243.

40. Chung C., et al. "Modulation of caseinate-stabilized model oilin-water emulsions with soy lecithin". Food Research International 122 (2019): 361-370.

41. Yulin Hu and Amarjeet Bassi. "Extraction of Biomolecules from Microalgae”. In Handbook of Microalgae-based Processes and Products. Elsevier Inc (2020).

42. García-Márquez E., et al. "Design of fish oil-in-water nanoemulsion by microfluidization". Innovative Food Science and Emerging Technologies 40 (2017): 87-91.

43. Zheng H., et al. "Effect of Oil Content and Emulsifier Type on the Properties and Antioxidant Activity of Sea Buckthorn Oilin-Water Emulsions". Journal of Food Quality (2020): 1540925.
44. Dahlawi S M., et al. "Formulation and characterization of oilin-water nanoemulsions stabilized by crude saponins isolated from onion skin waste". RSC Advances 10.65 (2020): 3970039707.

45. Reichert C L., et al. "Miscibility of Quillaja saponins with other co-surfactants under different $\mathrm{pH}$ values". Journal of Food Science 80.11 (2015): E2495-E2503.

46. Reichert C L., et al. "Influence of concentration ratio on emulsifying properties of Quillaja saponin - protein or lecithin mixed systems". Colloids and Surfaces A: Physicochemical and Engineering Aspects 561 (2019): 267-274.

47. Zhu Z., et al. "Comparison of natural and synthetic surfactants at forming and stabilizing nanoemulsions: Tea saponin, Quillaja saponin, and Tween 80". Journal of Colloid and Interface Science 536 (2018): 80-87.

48. Mession JL., et al. "Effect of globular pea proteins fractionation on their heat-induced aggregation and acid cold-set gelation". Food Hydrocolloids 46 (2015): 233-243.

49. McClements D J., "Theoretical prediction of emulsion color". Advances in Colloid and Interface Science 97 (2002): 63-89.

50. Consoli L., et al. "Sodium caseinate-corn starch hydrolysates conjugates obtained through the Maillard reaction as stabilizing agents in resveratrol-loaded emulsions". Food Hydrocolloids 84 (2018): 458-472.

51. Harnsilawat T., et al. "Stabilization of model beverage cloud emulsions using protein-polysaccharide electrostatic complexes formed at the oil-water interface". Journal of Agricultural and Food Chemistry 54.15 (2006): 5540-5547.

52. Tippel J., et al. "Composition of Quillaja saponin extract affects lipid oxidation in oil-in-water emulsions". Food Chemistry 221 (2017): 386-394.

53. Uluata S., et al. "Physical stability, autoxidation, and photosensitized oxidation of $\omega-3$ oils in nanoemulsions prepared with natural and synthetic surfactants". Journal of Agricultural and Food Chemistry 63.42 (2015): 9333-9340.

54. Kleber M E., et al. "Trans-fatty acids and mortality in patients referred for coronary angiography: The Ludwigshafen risk and cardiovascular health study". European Heart Journal 37.13 (2016): 1072-1078. 
55. Zock P L., et al. "Impact of myristic acid versus palmitic acid on serum lipid and lipoprotein levels in healthy women and men". Arteriosclerosis and Thrombosis, and Vascular Biology 14.4 (1994): 567-575.

56. Fleck J D., et al. "Saponins from Quillaja saponaria and Quillaja brasiliensis: Particular chemical characteristics and biological activities". Molecules 24.1 (2019): 171.

57. Sonwai Sopark and Punnee Ponprachanuvut. "Characterization of physicochemical and thermal properties and crystallization behavior of krabok (Irvingia malayana) and rambutan seed fats". Journal of Oleo Science 61.12 (2012): 671-679.

58. Tallima Hatem and Rashika El Ridi. "Arachidonic acid: Physiological roles and potential health benefits - A review". Journal of Advanced Research 11 (2018): 33-41.

59. Talib M A., et al. "Effect of Gum Arabic (Prebiotic) on Physicochemical and Organoleptic Properties of Yogurt (Probiotic)". In Gum Arabic: Structure, Properties, Application and Economics. Elsevier Inc, (2018).

60. Fernández, J., et al. "Colon microbiota fermentation of dietary prebiotics towards short-chain fatty acids and their roles as anti-inflammatory and antitumour agents: A review". Journal of Functional Foods 25 (2016): 511-522.

61. Ahmad A., et al. "A review on therapeutic potential of Nigella sativa: A miracle herb". Asian Pacific Journal of Tropical Biomedicine 3.5 (2013): 337-352.

62. Hannan M A., et al. "Black Cumin (Nigella sativa L.): A Comprehensive Review on Phytochemistry, Health Benefits, Molecular Pharmacology, and Safety". Nutrients 13.6 (2021): 1784.

\section{Assets from publication with us}

- Prompt Acknowledgement after receiving the article

- Thorough Double blinded peer review

- Rapid Publication

- Issue of Publication Certificate

- High visibility of your Published work

Website: www.actascientific.com/

Submit Article: www.actascientific.com/submission.php

Email us: editor@actascientific.com

Contact us: +919182824667

Citation: Roselina Karim., et al. "Effects of Alternative Ingredients and Processing Conditions on the Quality of Liquid Non-dairy Coffee Creamer: A Review". Acta Scientific Nutritional Health 6.1 (2022): 101-113. 